Chapter 2

\title{
Improvement of Soil Fertility with Use of Indigenous Resources in Lowland Rice Systems
}

\author{
Satoshi Nakamura, Roland Nuhu Issaka, \\ Israel K. Dzomeku, Monrawee Fukuda, \\ Mohammed Moro Buri, Vincent Kodjo Avornyo, \\ Eric Owusu Adjei, Joseph A. Awuni and \\ Satoshi Tobita
}

Additional information is available at the end of the chapter

http://dx.doi.org/10.5772/53209

\section{Introduction}

Low inherent soil fertility has been identified as a major cause for low rice yield in Sub-Saharan Africa (Buri et al., 2004; Senayah, et al., 2008; Buri et al., 2009; Issaka et al., 2009; Abe et al., 2010). The problem is compounded because farmers are not able to purchase fertilizer due to relatively high cost and therefore rely mostly on natural soil fertility which is low and declining. However, there are various organic materials that have the potential and can effectively contribute to improving soil fertility within the region. JIRCAS (2010) reported the quantity, quality and distribution of various organic materials that are available and suitable for supplementing soil fertility in Ghana. In this report, Rice straw (RS), Cow dung (CD), and Human excreta (HE) were evaluated in the Northern region which is located within the Guinea savanna zone and found them effective materials that can contribute in reducing chemical fertilizer application, and to improve soil fertility. RS, Poultry manure (PM), and Saw dust (SD) were evaluated in the Ashanti region located within the Equatorial forest zone. These two climate zones are common agricultural zones where lowland rice is cultivated in Africa.

RS, the commonest material within the two regions, is one of the most accessible materials to resource poor peasant farmers, because RS is produced in rice fields itself and therefore does not need to be transported. Therefore, the development of proper and improved management techniques of this material is essential for Ghanaian rice production. 
In the Northern region, $\mathrm{CD}$ and HE were selected as regional materials for agricultural use. These materials have been evaluated and used in some Asian countries as having high fertilizer effects (e.g. Austin et al., 2005, Matsui, 1997). However, in Ghana, these materials are considered as non-accessible resource because of lack of proper management technology, and psychological reasons (Coffie et al., 2005). In Ghana, it seems that gathering plant materials in the Northern region is more difficult than in the Ashanti region. Human and/or animal resource could be collected in settlement ecosystem through some life style or system innovations.

In the Ashanti region, PM and SD were selected. These materials are considered as having high agronomical potential especially in the Ashanti region. Commercial poultry farmers are generally concentrated in the Greater Accra and Ashanti regions hence almost 50\% of poultry manure is produced in these two regions (Quarcoo, 1996). So poultry manure is particularly accessible and available for rice production in the Ashanti region. SD is a byproduct material of lumbering industry which is popular in Ghana. Hence, its disposal has lately become a major problem for the government and timber industry.

This study therefore investigated the application effect of these selected organic materials on rice yield, and their proper processing methods for each organic matter application. The various processing (referred here as pre-treatment) include the following four treatments i.e. (i) ashing, (ii) charring, (iii) composting, and (iv) direct application. The effect of these four treatments on rice growth and yield were investigated. Organic materials have various forms, and each form has some advantages and disadvantages, as far as crop nutrition is concern. Therefore, this study investigated the best organic matter management option for rice production in Ghana, through the comparison of rice yield under four types pretreated i.e. ashed (ASH), charred (CH), composted (CO), or non-treated raw material (RW) organic materials application.

\section{Materials and methods}

\subsection{Research site}

Ghana has several agro-ecological zones but these can be broadly categorized into forest and savannah. The experiments were conducted at the University of Development Studies (UDS; N $09^{\circ} 24^{\prime} 19^{\prime \prime}$, W $000^{\circ} 58^{\prime} 14^{\prime \prime}$ ) located in the Northern region which lies within the Guinea savannah agro-ecological zone, and at the CSIR - Soil Research Institute (SRI; N 06 $45^{\prime} 18^{\prime \prime}$, W $\left.001^{\circ} 35^{\prime} 30^{\prime \prime}\right)$ which is in the Ashanti region and within the forest agro-ecological zone of the country. At UDS, the effect of rice straw (RS), cow dung (CD), and human excreta (HE) application on rice yield were investigated. At the CSIR-SRI, the effect of RS, poultry manure $(\mathrm{PM})$, and saw dust (SD) application on rice production was evaluated.

\subsection{Treatments}

Three types of organic materials that are potentially available were selected, for study site. Each of the organic material was applied to rice on the fields after pretreatment into ash $(\mathrm{ASH})$, charr $(\mathrm{CH})$, compost $(\mathrm{CO})$, and untreated raw material $(\mathrm{RW})$. The effect of Phosphate 
Rock (PR) on rice yield was also investigated by setting-up three levels of phosphorus i.e. $\mathrm{CON}$ as control $\left(0 \mathrm{kgP}_{2} \mathrm{O}_{5}\right.$ ha-1 $)$, BRP as (Burkina Faso phosphate rock) applied at $135 \mathrm{~kg}_{2} \mathrm{O}_{5}$ $\mathrm{ha}^{-1}$, and TSP as mineral fertilizer $\left(135 \mathrm{~kg} \mathrm{P}_{2} \mathrm{O}_{5}\right.$ ha $\left.^{-1}\right) .36$ treatments $(3 \times 4 \times 3)$ and withoutorganic material (WOM) application plot at 3 levels of $\mathrm{P}$ application and three replication., This gave a total of 117 plots in each station.

The quantities of the three types of organic materials applied were maintained as $3.2 \mathrm{~kg} \mathrm{P}_{2} \mathrm{O}_{5}$ ha $^{-1}$ at the Northern site, and applied directly to the soil surface. Compost was purchased from the market because there was not enough compost at that time. In Ashanti region, 3.2 $\mathrm{kg} \mathrm{P}_{2} \mathrm{O}_{5}$ ha $^{-1}$ of organic materials were applied as direct application, and $1 \mathrm{tha}^{-1}$ of materials were applied for pretreated organic materials. For all treatments, $30 \mathrm{~kg} \mathrm{~N} \mathrm{ha}^{-1}$ and $30 \mathrm{~kg} \mathrm{~K}_{2} \mathrm{O}$ $\mathrm{ha}^{-1}$ was applied as basal dressing.

Rice varieties in our trials were selected GR18 in Northern region, and Sikamo in Ashanti region. GR18 is reported to be one of the most popular varieties in Northern Ghana (Ghana Seed Company, 1988). Sikamo was recommended by Crops Research Institute (CRI), and was an improved variety for rain-fed lowlands rice cultivation, demonstrated in the 1990s by Ghana rice project.

The plant density was at a recommended rate of $20 \mathrm{~cm} \times 20 \mathrm{~cm}$ in each site.

\section{Results}

A 3-way analysis of variance (ANOVA) for rice grain yield under 36 treatments was conducted to verify the effect of organic matter application at each site, and to clarify the effect of interaction between three factors, i.e. type of organic material, pretreatment, and PR application. In this analysis, rice yield without organic matter application was excluded. The results of the 3-way ANOVA for rice grain yields did not show any significant difference between treatments and their interaction (Tables 1 and 2). Even though, all treatments were replicated three times, but it might not be enough to avoid specific variance of land condition for elucidation of statistical difference.

\begin{tabular}{lcccccccc}
\hline Factor & $\begin{array}{c}\text { Degrees of } \\
\text { freedom }\end{array}$ & Sum of & Mean & $\mathrm{F}$ & lsd $(5 \%)$ & $\mathrm{F}(5 \%)$ & significance \\
\hline A: Type of organic material & 2 & 0.41 & 0.21 & 0.07 & 0.79 & 3.13 & $\mathrm{~ns}$ \\
B: Pretreatment & 3 & 1.31 & 0.44 & 0.16 & 0.91 & 2.74 & $\mathrm{~ns}$ \\
C: Phosphate rock application & 2 & 0.61 & 0.30 & 0.11 & 0.79 & 3.13 & $\mathrm{~ns}$ \\
$\quad \mathrm{~A} \times \mathrm{B}$ & 6 & 5.04 & 0.84 & 0.30 & 1.57 & 2.23 & $\mathrm{~ns}$ \\
$\mathrm{~A} \times \mathrm{C}$ & 4 & 0.83 & 0.21 & 0.07 & 1.36 & 2.50 & $\mathrm{~ns}$ \\
$\mathrm{~B} \times \mathrm{C}$ & 6 & 2.38 & 0.40 & 0.14 & 1.57 & 2.23 & $\mathrm{~ns}$ \\
$\mathrm{~A} \times \mathrm{B} \times \mathrm{C}$ & 12 & 10.45 & 0.87 & 0.31 & 2.73 & 1.89 & $\mathrm{~ns}$ \\
$\mathrm{Error}$ & 70 & 196.10 & 2.80 & & & & \\
\hline
\end{tabular}

Table 1. 3-way ANOVA for rice grain yield in the Northern region 


\begin{tabular}{lccccccc}
\hline \multicolumn{1}{c}{ Factor } & $\begin{array}{c}\text { Degrees of } \\
\text { freedom }\end{array}$ & $\begin{array}{c}\text { Sum of } \\
\text { square }\end{array}$ & $\begin{array}{c}\text { Mean } \\
\text { square }\end{array}$ & $\begin{array}{c}\mathrm{F} \\
\text { value }\end{array}$ & lsd $(5 \%)$ & $\mathrm{F}(5 \%)$ & significance \\
\hline A: Type of organic material & 2 & 3.44 & 1.72 & 0.08 & 2.12 & 3.13 & $\mathrm{~ns}$ \\
B: Pretreatment & 3 & 3.84 & 1.28 & 0.06 & 2.45 & 2.74 & $\mathrm{~ns}$ \\
C: Phosphate rock application & 2 & 11.86 & 5.93 & 0.29 & 2.12 & 3.13 & $\mathrm{~ns}$ \\
$\mathrm{~A} \times \mathrm{B}$ & 6 & 3.76 & 0.63 & 0.03 & 4.24 & 2.23 & $\mathrm{~ns}$ \\
$\mathrm{~A} \times \mathrm{C}$ & 4 & 0.46 & 0.11 & 0.01 & 3.67 & 2.50 & $\mathrm{~ns}$ \\
$\mathrm{~B} \times \mathrm{C}$ & 6 & 7.50 & 1.25 & 0.06 & 4.24 & 2.23 & $\mathrm{~ns}$ \\
$\mathrm{~A} \times \mathrm{B} \times \mathrm{C}$ & 12 & 12.21 & 1.02 & 0.05 & 7.34 & 1.89 & $\mathrm{~ns}$ \\
Error & 70 & 1421.13 & 20.30 & & & & \\
\hline
\end{tabular}

Table 2. 3-way ANOVA for rice grain yield in the Ashanti region

\subsection{Effect of indigenous organic resources application on rice yield in Northern region}

Rice yield under various organic material applications are indicated in Table 3. Least significant differences (LSD) at $5 \%$ level are also shown in the Table. Statistical difference analysis, however, accord ANOVA priority to LSD. Mean value of rice grain yields under combined application of organic material, pretreatment, are indicated in Figure 1. The mean values were calculated by averaging of CON, BRP, and TSP for the three replications. The rice yield in Northern region generally showed higher value (e.g. $2.51 \mathrm{t}$ $\mathrm{ha}^{-1}$ at CO-HE mean value of CON, BRP, and TSP) compared with WOM (1.25 $\mathrm{t} \mathrm{ha}^{-1}$ in means value of CON, BRP, and TSP).

$\mathrm{CO}$ and RW showed relatively higher value in RS treatments. It seemed that ASH and $\mathrm{CH}$ treatment for rice straw had lost more nutrients than the other organic materials. Meanwhile, RW-RS and CO-RS have physical beneficial effect on soil fertility such as mulching effect.

In the $\mathrm{CD}$ treatments, $\mathrm{ASH}$ and $\mathrm{CH}$ showed higher value in $\mathrm{CON}$ treatment, and $\mathrm{CO}$ and RW showed higher value in BRP treatment. CD contained highest $\mathrm{P}_{2} \mathrm{O}_{5}$ contents $(1.72 \%)$ among three selected organic material. It maybe considered as the contribution of mineralized P from CD under combustion, that contributed to the increased rice grain yields.

The rice yields under $\mathrm{HE}$ application showed high value in $\mathrm{CH}$ and $\mathrm{CO}$ pretreatments. Especially under CON treatment, $\mathrm{CH}$ showed $2.97 \mathrm{t} \mathrm{ha}^{-1}$ of grain yield and $\mathrm{CO}$ showed $2.93 \mathrm{t} \mathrm{ha}^{-1}$ of grain yield, respectively.

Generally, organic materials application increased rice grain yields compared with WOM. Organic materials application showed pronounced effect especially in CON treatment, i.e. in RS 3.96 times, in CD 4.21 times, in HE 4.46 times higher than WOM rice yield, respectively. On the other hand, there were not significant effects of organic material applications on rice yield under TSP treatment. The rice yield under TSP treatment ranged from 82 to $91 \%$ against rice yield on WOM.

Ashing has disadvantageous of nutrient loss and/or green-house gas production with dry combustion. Meanwhile when the material is ashed, there is significant reduction in both weight and volume. Labour and cost of transportation is greatly reduced resulting in 
economic benefit and transportation efficiency. Ash contributes in the enhancement of soil fertility with mineralization of organic matter, in elimination of bad organic substances that may become plant growth inhibition factor, in supplement of Potassium and Silica (Anzai 1993).

Charring has similar advantages and disadvantages as in ashing in the short-term but is expected to show organic function compared with ashing. Recent studies reported that application of charred organic material could enhance crop production through increasing of soil organic matter, improvement of soil physical and biological properties (Glaser et al., 2002; Lehmann et al., 2003; Yeboah et al., 2009). And recently, the application of charred organic material has been focused as one of the important factor on the pedogenic process of Amazonian Dark Earth, that is known as tropical fertile soil with black colored surface (Nakamura et al., 2007)

It is well known that composted organic materials strongly contribute to crop production. Composting enhances the fertilizing capacity of an organic material. The $\mathrm{C} / \mathrm{N}$ ratio of an organic material decreases with composting, mineralization of the material also results in mineral nutrient concentration. Organic matter decomposition and fermentation, can reduce disease and pestilence risk due to increase in temperature. However, it is also known that composting requires knowledge for keeping fermentation condition i.e. water contents management. Composting is also laborious and the material is normally bulky requiring additional labour to convey the material to the field and apply. Therefore it may be a difficult technical option for farmers due to some of these reasons.

\begin{tabular}{|c|c|c|c|c|c|c|c|c|c|c|c|c|}
\hline & \multicolumn{4}{|c|}{ Rice Straw (RS) management } & \multicolumn{4}{|c|}{ Cow Dung (CD) management } & \multicolumn{4}{|c|}{ Human Excreta (HE) management } \\
\hline & $\mathrm{CON}$ & $\mathrm{BRP}$ & TSP & Ave & $\mathrm{CON}$ & $\mathrm{BRP}$ & TSP & Ave & $\mathrm{CON}$ & BRP & TSP & Ave \\
\hline WOM & 0.50 & 1.14 & 2.09 & 1.25 & 0.50 & 1.14 & 2.09 & 1.25 & 0.50 & 1.14 & 2.09 & 1.25 \\
\hline ASH & 1.53 & 1.99 & 1.65 & 1.72 & 2.48 & 1.83 & 1.92 & 2.08 & 1.80 & 1.13 & 1.83 & 1.59 \\
\hline $\mathrm{CH}$ & 1.46 & 1.51 & 1.87 & 1.61 & 2.62 & 1.88 & 1.63 & 2.04 & 2.97 & 1.76 & 1.24 & 1.99 \\
\hline $\mathrm{CO}$ & 2.40 & 1.92 & 1.74 & 2.02 & 1.96 & 2.32 & 1.67 & 1.98 & 2.93 & 2.54 & 2.06 & 2.51 \\
\hline RW & 2.61 & 1.57 & 2.38 & 2.19 & 1.43 & 2.68 & 1.67 & 1.93 & 1.31 & 1.82 & 2.34 & 1.83 \\
\hline Ave & 1.70 & 1.62 & 1.95 & 1.76 & 1.80 & 1.97 & 1.80 & 1.86 & 1.90 & 1.68 & 1.91 & 1.83 \\
\hline $\operatorname{LSD}(5 \%)$ & 1.70 & 1.42 & 1.67 & 0.86 & 1.90 & 2.27 & 1.29 & 0.96 & 1.97 & 0.92 & 1.62 & 0.88 \\
\hline \multicolumn{13}{|c|}{ Effectiveness of organic matter application } \\
\hline WOM & 1.00 & 1.00 & 1.00 & 1.00 & 1.00 & 1.00 & 1.00 & 1.00 & 1.00 & 1.00 & 1.00 & 1.00 \\
\hline ASH & 3.03 & 1.74 & 0.79 & 1.38 & 4.92 & 1.61 & 0.92 & 1.67 & 3.57 & 0.99 & 0.87 & 1.27 \\
\hline $\mathrm{CH}$ & 2.89 & 1.32 & 0.89 & 1.29 & 5.20 & 1.65 & 0.78 & 1.64 & 5.88 & 1.55 & 0.59 & 1.60 \\
\hline $\mathrm{CO}$ & 4.76 & 1.69 & 0.83 & 1.62 & 3.89 & 2.04 & 0.80 & 1.59 & 5.80 & 2.23 & 0.98 & 2.01 \\
\hline RW & 5.18 & 1.38 & 1.14 & 1.76 & 2.84 & 2.35 & 0.80 & 1.55 & 2.60 & 1.60 & 1.12 & 1.47 \\
\hline Ave & 3.96 & 1.53 & 0.91 & 1.51 & 4.21 & 1.91 & 0.82 & 1.61 & 4.46 & 1.59 & 0.89 & 1.59 \\
\hline
\end{tabular}

Grain yield: $\left(\mathrm{t} \mathrm{ha}{ }^{-1}\right)$; CON: Non-P application, BRP: Burkina Faso Phosphate Rock application, TSP: Triple Super Phosphate application, WOM: without organic material, ASH: ashing, $\mathrm{CH}$ : charring, CO: composting, RW: raw material,

Effectiveness of organic matter application: The rice grain yield at each plot / the rice grain yield at WOM under same $\mathrm{P}$ management condition.

Table 3. Rice grain yield under organic and pretreated materials in Northern region 


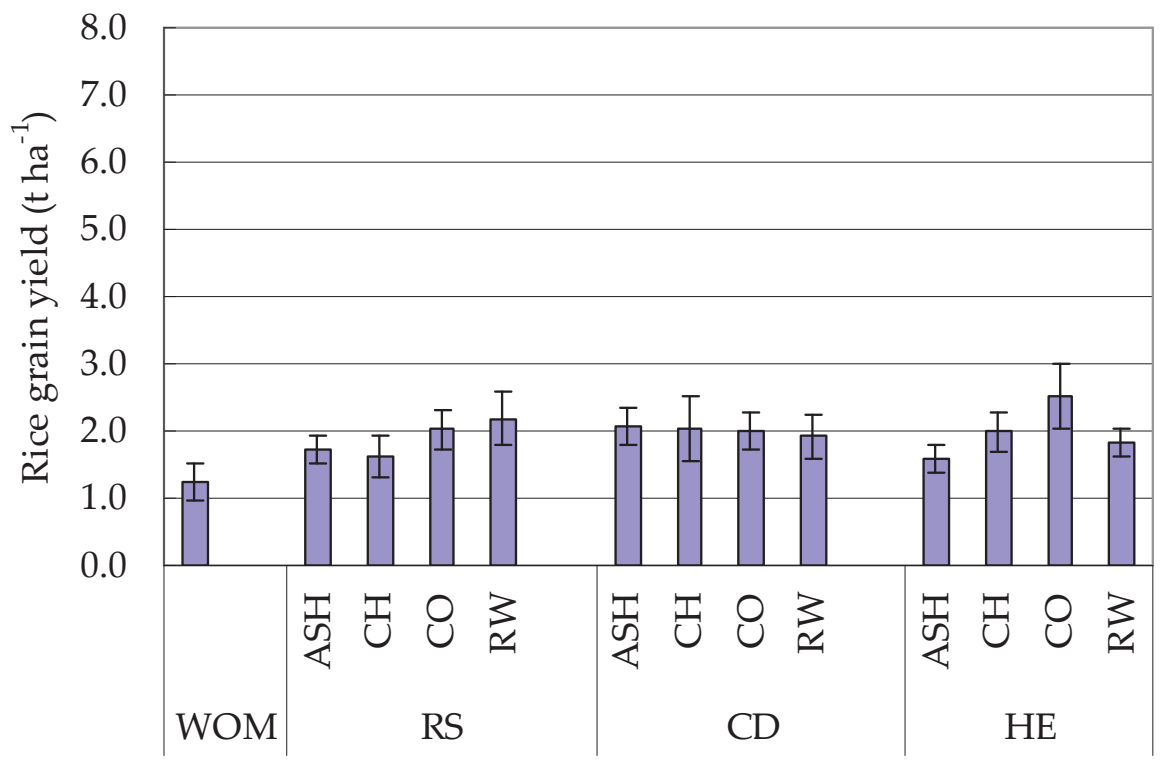

Figure 1. Effect of organic matter application on rice grain yield in Northern region. Mean values of CON, BRP, and TSP treatment are indicated. WOM: without organic matter, RS: rice straw, CD: cow dung, HE: human excreta, ASH: ashing, $\mathrm{CH}$ : charring, $\mathrm{CO}$ : composting, RW: raw material

\subsection{Effect of indigenous organic resources application on rice yield in Ashanti region}

Rice yields under various organic materials applications in Ashanti region are shown in Table 4 and Figure 2. The significant difference by 3-way ANOVA was not found as the same as Northern region. The cultivar used in Ashanti region (Sikamo) was different from Northern region (GR18), so rice yields could not be simply compared between the two research sites.

In the RS treatment, the mean rice yield values for CON, BRP, TSP rice yields showed higher value than WOM, but RW-RS showed relatively lower values than the other treatments. The RW-RS was the best harvested RS treatment in Northern region, so there were different effectiveness trend of RS treatment between Northern and Ashanti region. Northern region is located in Guinea-Savannah zone, and has little annual precipitation. Soils were kept under upland condition over a long time. Ashanti region is in the Equatorial Forest zone that has higher rainfall and that lowland rice can be cultivated under submerged condition throughout the year. Probably the difference of RW-RS effect on rice yield between the two sites was attributed to difference of organic matter decomposition rate caused by variation in water conditions. 


\begin{tabular}{|c|c|c|c|c|c|c|c|c|c|c|c|c|}
\hline & \multicolumn{4}{|c|}{ Rice Straw (RS) management } & \multicolumn{4}{|c|}{ Poultry Manure (PM) management } & \multicolumn{4}{|c|}{ Saw Dust (SD) management } \\
\hline & $\mathrm{CON}$ & BRP & TSP & Ave & $\mathrm{CON}$ & BRP & TSP & Ave & $\mathrm{CON}$ & BRP & TSP & Ave \\
\hline WOM & 5.10 & 6.20 & 5.27 & 5.52 & 5.10 & 6.20 & 5.27 & 5.52 & 5.10 & 6.20 & 5.27 & 5.52 \\
\hline ASH & 6.03 & 6.43 & 7.27 & 6.58 & 5.20 & 6.83 & 7.20 & 6.41 & 5.63 & 6.80 & 6.47 & 6.30 \\
\hline $\mathrm{CH}$ & 6.67 & 6.10 & 7.27 & 6.68 & 5.93 & 6.17 & 7.27 & 6.46 & 6.17 & 6.63 & 6.13 & 6.31 \\
\hline $\mathrm{CO}$ & 5.73 & 7.27 & 6.93 & 6.64 & 6.43 & 7.13 & 6.70 & 6.76 & 6.03 & 5.57 & 7.87 & 6.49 \\
\hline RW & 6.30 & 6.47 & 6.20 & 6.32 & 6.20 & 6.73 & 6.77 & 6.57 & 5.33 & 5.90 & 5.17 & 5.47 \\
\hline Ave & 5.97 & 6.49 & 6.59 & 6.35 & 5.77 & 6.61 & 6.64 & 6.34 & 5.65 & 6.22 & 6.18 & 6.02 \\
\hline $\operatorname{LSD}(5 \%)$ & 0.95 & 2.14 & 2.05 & 0.95 & 1.03 & 1.80 & 1.93 & 0.92 & 1.23 & 2.18 & 1.78 & 1.04 \\
\hline \multicolumn{13}{|c|}{ Effectiveness of organic matter application } \\
\hline WOM & 1.00 & 1.00 & 1.00 & 1.00 & 1.00 & 1.00 & 1.00 & 1.00 & 1.00 & 1.00 & 1.00 & 1.00 \\
\hline ASH & 1.18 & 1.04 & 1.38 & 1.19 & 1.02 & 1.10 & 1.37 & 1.16 & 1.10 & 1.10 & 1.23 & 1.14 \\
\hline $\mathrm{CH}$ & 1.31 & 0.98 & 1.38 & 1.21 & 1.16 & 0.99 & 1.38 & 1.17 & 1.21 & 1.07 & 1.16 & 1.14 \\
\hline $\mathrm{CO}$ & 1.12 & 1.17 & 1.32 & 1.20 & 1.26 & 1.15 & 1.27 & 1.22 & 1.18 & 0.90 & 1.49 & 1.18 \\
\hline RW & 1.24 & 1.04 & 1.18 & 1.14 & 1.22 & 1.09 & 1.28 & 1.19 & 1.05 & 0.95 & 0.98 & 0.99 \\
\hline Ave & 1.21 & 1.06 & 1.31 & 1.19 & 1.17 & 1.08 & 1.33 & 1.19 & 1.14 & 1.00 & 1.22 & 1.11 \\
\hline
\end{tabular}

Grain yield: (t ha-1); CON: Non-P application, BRP: Burkina Faso Phosphate Rock application, TSP: Triple Super Phosphate application, WOM: without organic material, $\mathrm{ASH}$ : ashing, $\mathrm{CH}$ : charring, $\mathrm{CO}$ : composting, RW: raw material,

Effectiveness of organic matter application: The rice grain yield at each plot / the rice grain yield at WOM under same P management condition.

Table 4. Rice grain yield under organic and pretreated materials in Ashanti region

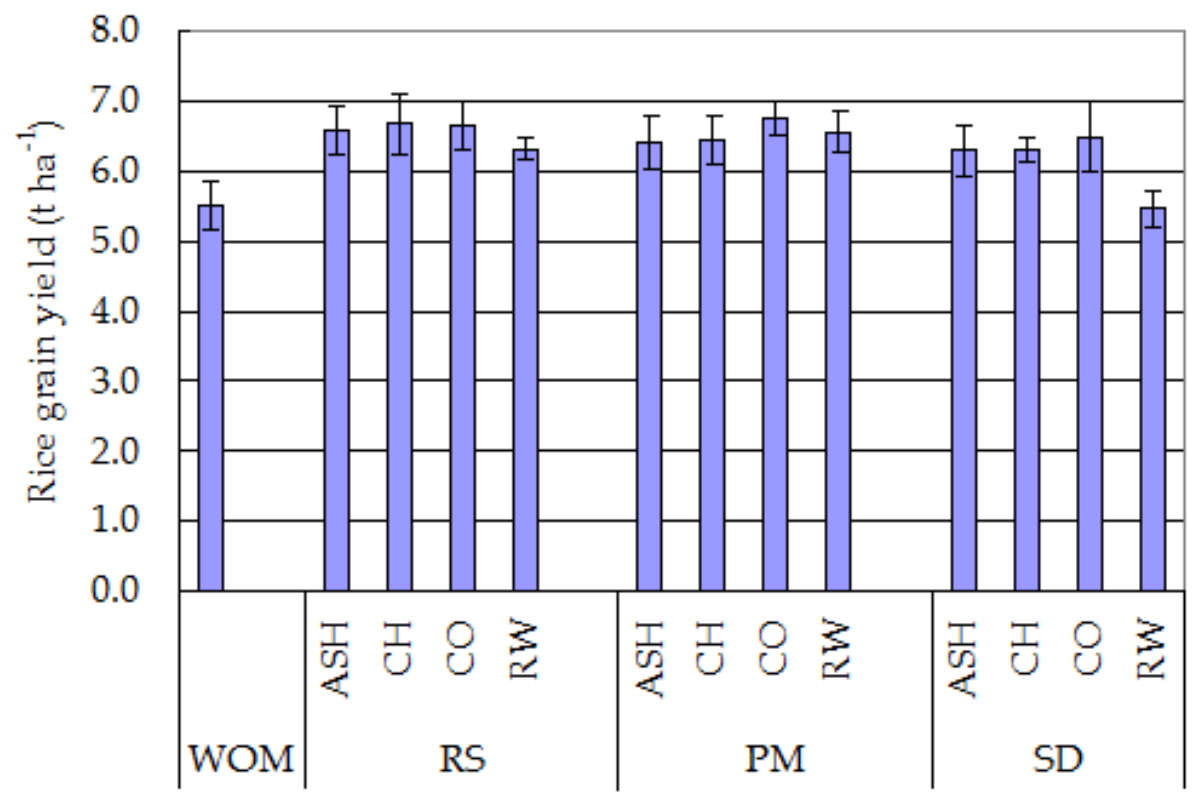

Figure 2. Effect of organic matter application on rice grain yield in Ashanti region. Means values of CON, BRP, and TSP treatment are indicated. WOM: without organic matter, RS: rice straw, PM: poultry manure, SD: saw dust ASH: ashing, $\mathrm{CH}$ : charring, $\mathrm{CO}$ : composting, RW: raw material 
The application of poultry manure resulted in higher yield except $\mathrm{ASH}$ and $\mathrm{CH}$ under $\mathrm{CON}$ treatment. However, ASH-PM showed low yield (5.20 t ha $\left.{ }^{-1}\right)$ under CON treatment, but showed high yield under BPR and TSP treatments (6.83 and $\left.7.20 \mathrm{t} \mathrm{ha}^{-1}\right)$, respectively.

Under the SD application, RW-SD produced a lower value compared with other SD application. RW-SD under all three P treatments showed a similar yield as WOM (Effectiveness against WOM: 1.05 at CON, 0.95 at BRP, 0.98 at TSP). Only the RW-SD did not show the positive effect of organic matter application on rice yield. The RW-SD in Ashanti region was direct application of woody material for submerged condition. So, decomposition rate and plant nutrient release rate seemed to be extremely slow, and thus causing nitrogen starvation for the treatment.

\subsection{The combination effect of various organic materials and phosphate rock application}

The agronomic efficiencies to TSP under various organic matter applications are shown in Table 5. Agronomic efficiency was calculated from the difference in grain yield $\left(\mathrm{t} \mathrm{ha} \mathrm{a}^{-1}\right)$ of PR to those of TSP treatment. This efficiency can be considered as the indicator of BRP being a possible alternative to TSP. According to FAO (2004), BPR direct application showed $97 \%$ of agronomic efficiency in lowland rice cultivation.

Under this study and within the Northern region in Ghana, the agronomic efficiency of BPR direct application against TSP was relatively lower in WOM, RW-RS, ASH-HE (54, 66, 62\%, respectively). Treatments of ASH-RS, RW-CD, CO-CD, CH-HE, CO-HE showed efficiency of over $120 \%$, suggested that combined application of PR and organic materials was effective in PR application. It is well known that organic matter application is one of the effective techniques to solubilize PR. This may be so due to PR dissolution in organic acids produced by microorganisms, through decomposition of easily decomposable organic substances.

On the other hand, within the Ashanti region, only CO-SD showed a lower value (71\%). The other treatments including WOM gave similar trend with higher values that ranged from $84 \%$ to $118 \%$. This result shows that agronomic efficiency did not increased by organic matter application. These results do not only indicated that BPR can be use directly as alternative fertilizer, but also indicated that there are not clear positive effects of organic matter application on PR agronomic efficiency enhancement.

\begin{tabular}{ccccccccc}
\hline & \multicolumn{3}{c}{ Northern } & & \multicolumn{3}{c}{ Ashanti } \\
\cline { 2 - 4 } \cline { 6 - 8 } & RS & CD & HE & & RS & PM & SD \\
\hline ASH & 121 & 95 & 62 & & 89 & 95 & 105 \\
CH & 81 & 115 & 142 & & 84 & 85 & 108 \\
CO & 111 & 139 & 123 & & 105 & 106 & 71 \\
RW & 66 & 160 & 78 & & 104 & 100 & 114 \\
& & & & & & \\
WOM & 54 & & & & 118 & & \\
\hline
\end{tabular}

RS: rice straw, CD: cow dung, HE: human excreta, PM: poultry manure, SD: saw dust, WOM: without organic material, ASH: ashing, $\mathrm{CH}$ : charring, CO: composting, RW: raw material directly applied

Table 5. Effect of various organic material application on changes of agronomic efficiency (\%) in BPR direct application against TSP application 


\section{Conclusions and recommendations}

Rice grain yields generally increased with the application of the various organic matters. Grain yields under organic matter application showed approximately 1.5 to 1.6 times higher than those of WOM in Northern region, and 1.1 to 1.2 times higher than WOM in Ashanti region. However in some case e.g. RW-SD, did not show any positive effect of application on rice yield, and so the proper pretreatment for each organic resources need to be selected.

\subsection{Suggestion for indigenous organic material application in Northern region, for rain- fed lowland rice cultivation in Savannah zone}

The best promising organic material for agricultural use in Northern region is rice straw (RS). CO-RS and RW-RS treatment showed high positive effect on rice yield in the Northern region trial. It seems adequate amount of mineral plant nutrients were supplied due to decomposition of RS and that soil physical and biological properties were enhanced. On the other hand, CH-RS and ASH-RS also showed positive effect on rice yield, however, it should be considered that charring needs input of labor and capital, and that ashing will impact the environmental negatively. Moreover, ashing process can reduce effectiveness of soil physical and biological properties observed under CO and RW application.

CD application showed high yield in all pretreated plots. It is well known that CD application is effective for rice production. In the Northern region, however, it is far from recommended materials because of difficulty in material gathering. Most of CD in this region was produced by cattle grazing, that means farmer needs to collect CD scattered throughout savannah forest. This study indicated that CD has similar effect on rice yield compared with other organic materials. The use of $\mathrm{CD}$ in rice cultivation can be as popular as RS due to both availability and accessibility. While RS is readily available in the rice fields extra labour is require to search and collect CD. However, after using CD as fuel $\mathrm{CH}-\mathrm{CD}$ and $\mathrm{ASH}-\mathrm{CD}$ can be used in rice production since these materials increased rice yield significantly.

Rice yields average of HE application was almost same as those of CD. Improvement of crop productivity has been reported by many existing studies. However it also has been mentioned that HE usage has difficulty to diffuse for farmers because of hygienic risk and psychological avoidance. These obstacles can be resolved by either combustion process such as $\mathrm{CH}$ and $\mathrm{ASH}$, or composting process. CO-HE indicated highest yield among four pretreatment in HE treatments, the yield was almost twice higher than WOM.

According to the results from Northern region trial, authors suggest that CD and/or HE composting based on RS usage should be well examined as the effective and affordable technical options for farmers. HE composting still have the difficulty of gathering, but technology introduction on collecting and separating urine and feces, such as Eco-San toilet, will open the way for proper management of HE, especially in Northern region. Moreover CD and HE composting based RS can be expected to increase RP application effect on rice yield. 


\subsection{Suggestion for indigenous organic material application in Ashanti region, under water controlled lowland rice cultivation in Equatorial forest zone}

Similar to what was observed in Northern region, the use of RS is considered as an effective resource for rice production in Ashanti region, because of its high accessibility. However, unlike the Northern region, RW-RS in Ashanti region showed a smaller effect on rice production than the other treatments. Most rice fields in Ashanti region are irrigated and can be used to cultivate throughout the year. Therefore, rice fields are generally maintained under submerged condition for long periods hence decomposition rate of organic matter will be relatively slow. Hence, RW-RS application is discouraged because its effect on rice yield is not pronounced, and a possible risk of nitrogen starvation.

Poultry manure with every pretreatment showed high positive effect on rice yield enhancement, especially in CO-PM. Poultry manure is a popular organic material that is an effective P source, and that is highly accessible in the Ashanti region.

In the SD treatment, RW-SD showed lower value (5.47 $\left.\mathrm{t} \mathrm{ha}^{-1}\right)$ than WOM of rice yield (5.52 $\mathrm{t} \mathrm{ha}^{-1}$ ). Similar to RW-RS, direct application of SD generally has the problem due to its high $\mathrm{C} / \mathrm{N}$ ratio. Moreover SD composting is also difficult because SD consist of woody material that contains resistant organic matter. To avoid plant damage by organic acids and/or nitrogen starvation, SD composting needs to take a long time for decomposition and fermentation. Combustion treatment, which take shorter time and is easy to practice $(\mathrm{CH}$ and $\mathrm{ASH})$ is affordable and effective for agricultural usage in Ashanti region. The possibility of composting through inoculation with microorganisms should not be excluded from future investigation.

In the organic material application in Ashanti region, all treatment except direct application of RS and SD showed positive effect on rice grain yield. It is suggested that ASH-RS, CH-RS, ASH-SD, CH-SD, and composting RS or SD combined with PM, and also RW-PM, are evaluated as promising technical options that are accessible and effective for rice cultivation in Ashanti region. These selected options showed relatively high value not only in rice yield but also in agronomic efficiency of BPR application. The effect of organic material application on enhancement of PR solubility was smaller compared with the effect observed in Northern region. However, direct application of PR in this region indicated high agronomical efficiency to TSP application, and means PR has possibility of alternative usage against TSP. Further investigation need to be conducted on the effect of RP combined with organic material application on rice yield.

\section{Acknowledgement}

This investigation was conducted under the project "Improvement of Soil Fertility with Use of Indigenous Resources in Rice Systems of Sub-Sahara Africa', which was funded by the Ministry of Agriculture, Forestry and Fisheries (MAFF), Japan. The authors are grateful to the entire staff of CSIR-SRI, UDS both in Ghana and JIRCAS for their technical supports. 


\section{Author details}

Satoshi Nakamura ${ }^{1}$, Roland Nuhu Issaka ${ }^{2}$, Israel K. Dzomeku ${ }^{3}$, Monrawee Fukuda ${ }^{1}$, Mohammed Moro Buri ${ }^{2}$, Vincent Kodjo Avornyo ${ }^{3}$, Eric Owusu Adjei ${ }^{2}$, Joseph A. Awuni ${ }^{3}$ and Satoshi Tobita ${ }^{1}$

1 Japan International Research Center for Agricultural Sciences (JIRCAS), Ohwashi, Tsukuba, Ibaraki, Japan

2 CSIR-Soil Research Institute (SRI), Academy Post Office, Kwadaso - Kumasi, Ghana

3 University for Development Studies (UDS) Faculty of Agriculture, Department of Agronomy, Tamale, Ghana

\section{References}

[1] Abe S, Buri MM, Issaka RN, Kiepe P, Wakatsuki T. 2010: Soil Fertility Potential for Rice Production in West African Lowlands. JARQ. 44 (4), 343 - 355.

[2] Anzai T 1993: Effect of Succesive Applications of Organic Matter on the Cultivation of Paddy Rice in Gley Paddy Soil III. Influence of successive applications of rice straw ash on growth, yield and nutrient uptake of rice and on chemical properties of paddy soil. Bull. Chiba Agric. Exp. Stn. 34, 13-21.

[3] Austin LM, Duncker LC, Matsebe GN, Phasha MC, Cloete TE 2005: Ecological sanitation - Literature review. WRC Report No TT 246/05. WRC, Pretoria.

[4] Buri MM, Iassaka RN, Fujii H, Wakatsuki, T. 2010: Comparison of Soil Nutrient status of some Rice growing Environments in the major Agro-ecological zones of Ghana. International Journal of Food, Agriculture \& Environment Vol. 8, No. 1, 384-388.

[5] Buri MM, Issaka RN, Wakatsuki T, Otoo E. 2004: Soil organic amendments and mineral fertilizers: Options for sustainable lowland rice production in the Forest agroecology of Ghana. Agriculture and Food Science Journal of Ghana, 3, 237-248.

[6] Cofie OO, Kranjac-Berisavljevic G Dreschel P 2005: The use of human waste for periurban agriculture in Northern Ghana. Renewable Agr. Food Sys, 20, 73-80.

[7] Food and Agriculture Organization 2004: Use of phosphate rocks for sustainable agriculture. FAO Fertilizer and Plant Nutrition Bulletin No.13, Food and Agriculture Organization of the United Nations, Rome.

[8] Ghana Seed Company (1988): Regional Branch Annual Report, Tamale.

[9] Issaka RN, Buri MM. Wakatsuki T. 2009: Effect of soil and water management practices on the growth and yield of rice in the forest agro-ecology of Ghana. J. Food Agric. Environ., 7 (1), 214-218. 
[10] Issaka, R.N., Buri, M. M.. and Wakatsuki, T. 2009. Effect of soil and water management practices on the growth and yield of rice in the forest agro-ecology of Ghana. Journal of Food, Agriculture \& Environment Vol.7 (1) : 214-218.

[11] JIRCAS 2010: The Study of Improvement of Soil Fertility with Use of Indigenous Resources in Rice Systems of sub-Sahara Africa. Business Report 2009.

[12] Lehmann J, Pereira da Silver Jr J, Steiner C, Nehls T, Zech W, Glaser, B 2003: Nutrient availability and leaching in an archaeological Anthrosols and a Ferralsol of the Central Amazon basin: fertilizer, manure and charcoal amendments. Plant Soil, 249, 343-357.

[13] Matsui S 1997: Nightsoil collection and treatment: Japanese practice and suggestions for sanitation of other areas in the globe. Sida Sanitation Workshop. Balingsholm, Sweden.

[14] Quarcoo AND 1996: A characterization and decomposition study of poultry manure. A BSc Thesis submitted to the University of Science \& Technology, Kumasi Ghana.

[15] Senayah JK, Issaka RN, Dedzoe CD 2008: Characteristics of Major Lowland Ricegrowing Soils in the Guinea Savanna Voltaian Basin of Ghana. Agriculture and Food Science Journal of Ghana, 6, 445-458.

[16] Yeboah E, Ofori P, Quansah G, Dugan E, Sohi S 2009: Improving soil productivity through biochar amendments to soils. African Journal of Environmental Science and Technology, 3 . 